\title{
Exocytosis of peptide functionalized gold nanoparticles in endothelial cells $\uparrow$
}

\author{
Dorota Bartczak, ${ }^{a}$ Simone Nitti, ${ }^{c}$ Timothy M. Millar ${ }^{b}$ and Antonios G. Kanaras $* a$ \\ Received 1st May 2012, Accepted 13th June 2012 \\ DOI: $10.1039 / \mathrm{c} 2 \mathrm{nr} 31064 \mathrm{c}$
}

\begin{abstract}
We present the exocytosis profile of two types of peptide-coated nanoparticles, which have similar charge and size but different functionality. While one kind of particles appears to progressively exocytose, the other one has a more complex profile, suggesting that some of the particles are re-uptaken by the cells. Both types of particles retain their colloidal stability after exocytosis.
\end{abstract}

Understanding the interactions of functional nanoparticles with biological cells is of tremendous importance not only for new developments in sensing, imaging and therapy but also for realizing the fundamental cellular mechanisms and cytotoxicity of nanomaterials. ${ }^{1-5}$ With an accumulated knowledge of how the size, shape and functionality of nanomaterials influence their fate in cells, one should be able to synthesize nanoparticles on demand, with appropriate functionality and which are best suited to a particular application. This means that particles would be designed to (a) be taken up by the cell in desirable numbers, (b) deliberately escape from the endosomes, (c) access the cytoplasm and migrate selectively through the cell for a given time, (d) target specific compartments and organelles (i.e. nucleus, mitochondria) to perform desired tasks and (e) exocytose in high numbers leaving the cell intact. Following these aims, several research groups have successfully investigated various aspects of interactions between functional nanoparticulate systems and cells..$^{6-14}$ For example, Brust and co-workers shed light on the intracellular fate of spherical gold nanoparticles coated with cell penetrating peptides and suggested ways of pre-programming nanoparticle migration within the cytoplasm. ${ }^{15,16}$ Alternatively Mirkin and colleagues performed a systematic study on the internalization rate of DNA modified gold nanoparticles and suggested new directions for targeted gene therapy. ${ }^{17,18}$ Our group and others have investigated how the size, shape and charge of nanoparticles influence their cellular uptake, ${ }^{19-23}$ and how the number of endocytosed particles correlates with the nanoparticles' heating efficiency during laser hyperthermia. ${ }^{20,24}$

Despite the extensive work on gold nanoparticle uptake and intracellular fate, ${ }^{7,25}$ a very limited number of papers have discussed

${ }^{a}$ Institute for Life Sciences and Physics and Astronomy, Faculty of Physical and Applied Sciences, Highfield, University of Southampton, Southampton, UK SO17 1BJ. E-mail: a.kanaras@soton.ac.uk; Fax: +44 (0) 2380593910; Tel: +44 (0)2380592466

${ }^{b}$ Faculty of Medicine, University of Southampton, Southampton, UK 'Instituto Italiano di Technologia, Via Morego 30, 16163 Genova, Italy $\dagger$ Electronic supplementary information (ESI) available: ICP-AES DLS and zeta potential measurements. See DOI: $10.1039 / \mathrm{c} 2 \mathrm{nr} 31064 \mathrm{c}$ the exocytosis of functional gold nanoparticles. ${ }^{26}$ Since gold is one of the most promising candidates for biomedical applications in the near future, exocytosis studies are of great importance, because they are directly correlated with chronic cytotoxicity and nanoparticle intracellular retention times.

In this paper we investigated the cellular uptake and exocytosis of two types of peptide functionalized gold nanospheres by an important category of mammalian cells, namely human endothelial cells (HUVECs). The specific types of particles were chosen due to their ease of preparation and particular function. To keep our studies consistent, both types of nanoparticles were designed to have similar hydrodynamic size and charge. The first batch of nanoparticles ('inhibitors') was functionalized with the KATWLPPR peptide. In the past, these particles have been shown to bind to receptors on the endothelial plasma membrane, promoting the down-regulation of angiogenic genes. ${ }^{19}$ The second batch of nanoparticles was modified with the KPRQPSLP peptide, and they have been employed in our previous studies as 'mutants' that do not interact with known plasma membrane receptors and are simply endocytosed. ${ }^{19}$ Thus, our work is significant because it monitors the exocytosis of nanoparticles taking into account two important parameters: (a) the specialized category of cells (human endothelial cells), which participate in various critical biological processes and (b) the types of functional nanoparticles, which, although they have similar size and charge, undergo endocytosis in different ways; the 'inhibitors' via specific receptor-mediated endocytosis and the 'mutants' via a non-specific pathway.

A schematic illustration of the nanoparticles used in these experiments is shown in Scheme 1. The functionalized particles, namely, $\mathrm{P}_{\text {mut }}$-OEG-NPs (for the 'mutants') and $\mathrm{P}_{\text {inh-OEG-NPs (for the }}$ 'inhibitors'), have been developed following protocols described in our previous studies. ${ }^{19}$ Briefly, gold nanospheres synthesized according to the Turkevich method, ${ }^{27}$ with an average size of $15 \pm$ $2 \mathrm{~nm}$, were coated with monocarboxy (1-mercaptoundec-11-yl) hexaethylene glycol (OEG) and coupled with peptides following an optimized EDC/sulfo-NHS method. ${ }^{28}$

For the cellular uptake studies, endothelial cells were treated with the particles for $4 \mathrm{~h}$ at $37^{\circ} \mathrm{C}$, then the media was removed and the adherent cells were washed with buffer, harvested from the culture dish, digested and further analysed for their gold content using ICP-AES. The results obtained from several independent ICP measurements (see ESI $\dagger$ ) show that the peptide coated nanoparticles are taken up by the cells in greater numbers than the particles coated only with OEG. We have recently reported that spherical OEG coated nanoparticles are taken up by endothelial cells in the range of 


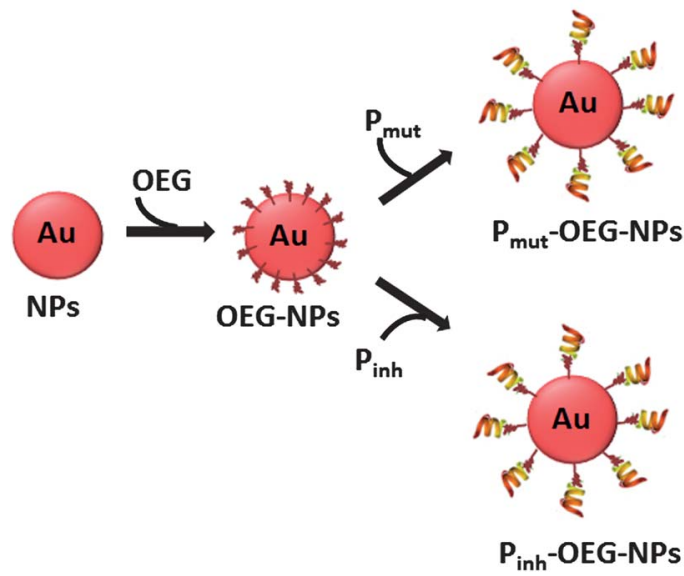

Scheme 1 Schematic illustration of the nanoparticles used in the cellular uptake and exocytosis studies. The gold nanospheres have an average size of $15 \mathrm{~nm}$. The particles are coated first with an oligoethylene glycol derivative (OEG) and then coupled to the $P_{\text {mut }}$ (KPRQPSLP) or $P_{\text {inh }}$ (KATWLPPR) peptide.

2000 nanoparticles per cell. ${ }^{20}$ Here, when the particles are coupled to $\mathrm{P}_{\text {inh }}$ or $\mathrm{P}_{\mathrm{mut}}$, a tremendous increase in nanoparticle uptake to the order of 300000 nanoparticles per cell is observed after $4 \mathrm{~h}$ of treatment. Since the change of nanoparticle charge or size is not significant in comparison to the OEG nanoparticles, we attribute the difference in uptake to the peptide functionality. In the previous work, we suggested that the $\mathrm{P}_{\text {mut }}$ coated nanoparticles are taken up by a non-specific endocytosis pathway while the $\mathrm{P}_{\text {inh }}$ coated nanoparticles are endocytosed predominantly via a specific NRP-1 receptor-mediated pathway. ${ }^{19}$ Although, the $\mathrm{P}_{\text {inh }}$ and $\mathrm{P}_{\text {mut }}$ coated nanoparticles are internalized following different routes, we did not observe any large variation in the numbers of the two types of particles found per cell after $4 \mathrm{~h}$ (see ESI $\dagger$ ). This led us to an assumption that the higher number of internalized peptide coated particles may be attributed to the secondary interactions with the biological medium. Indeed, the presence of the peptides may promote non-specific interactions of the nanoparticles with serum proteins resulting in an increase of nanoparticle internalization. Our group is involved in experiments to further support this hypothesis.

A critical experiment to better understand the interactions of the peptide-coated nanoparticles with the endothelial cells is to study the nanoparticles' exocytosis. For these studies the cells were treated with the particles for $4 \mathrm{~h}$ at $37^{\circ} \mathrm{C}$. They were then washed with buffer and incubated in the fresh media for $2 \mathrm{~h}, 4 \mathrm{~h}$ or $6 \mathrm{~h}$. To ensure the reliability of our experiments the gold content was estimated in the cells and in the supernatant. The experiments were performed in triplicate and for each sample the content of gold was measured using ICP-AES. Fig. 1 shows the nanoparticle profiles obtained for the 'mutant' and the 'inhibitor' nanoparticles.

As can be seen, in both experiments, the amount of nanoparticles found in the cells and in the supernatant adds up to the total number of nanoparticles initially found in the cells after $4 \mathrm{~h}$ of incubation with the particles. In case of the 'inhibitor' we observed that after $2 \mathrm{~h}$ less than $20 \%$ of the uptaken nanoparticles are exocytosed, with a progressive increase at $4 \mathrm{~h}$ and $6 \mathrm{~h}$. However, most of the nanoparticles are retained in the cells for a period of $6 \mathrm{~h}$. In contrast to the 'inhibitors', the 'mutants' present a different profile of exocytosis. Although after $2 \mathrm{~h}$ almost $25 \%$ of the uptaken nanoparticles are
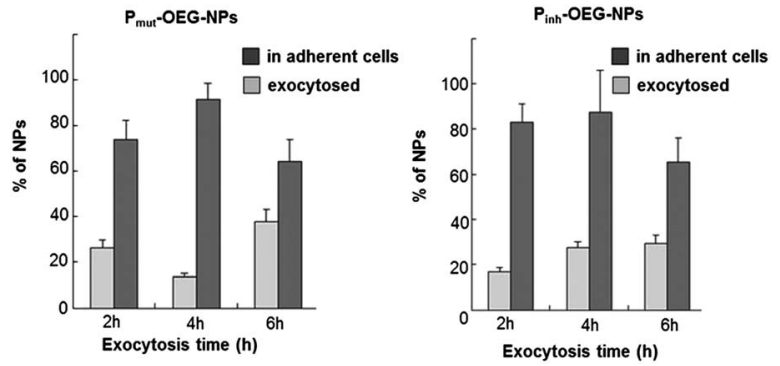

Fig. 1 Endocytosis and exocytosis profile of peptide coated nanoparticles. The cells are treated with $\mathrm{P}_{\text {mut }}$ or $\mathrm{P}_{\text {inh }}$ coated nanoparticles for $4 \mathrm{~h}$, washed and incubated in fresh media for $2 \mathrm{~h}, 4 \mathrm{~h}$ and $6 \mathrm{~h}$. The amount of particles in the cells and outside of the cells (in the media) is estimated in each case. The $y$ axis value is presented as the percentage of the particles found to be taken in by the cells after the initial $4 \mathrm{~h}$ treatment.

found outside the cell, after $4 \mathrm{~h}$ only $10 \%$ is exocytosed. This observation is accompanied by an increase in the amount of gold nanoparticles found in the cells. After $6 \mathrm{~h}$ almost $40 \%$ of the 'mutant' particles are found to be outside the cells, in agreement with the measurement of about $60 \%$ of particles remaining within the cells.

Overall, the comparison between the two different types of particles shows that more than half of the particles, in both cases (almost $60 \%$ ), remain in the cells after $6 \mathrm{~h}$. While the 'inhibitors' appear to progressively exocytose, the 'mutants' have a more complex profile, suggesting that some of the particles (about 10\%) are re-uptaken by the cells after $4 \mathrm{~h}$. These data are supported by an increase in the amount of 'mutant' particles found in the cells after $4 \mathrm{~h}$. The variations in exocytosis profile between the two different types of particles highlights the difference in the peptide capping, which is strongly correlated with the nanoparticle uptake mechanism and the fate of particles in the cells.

In the cell, nanoparticles are exposed to a stringent biochemical environment, and although capped with organics, a question about their colloidal stability when they are exocytosed remains. Therefore, we measured the hydrodynamic diameter and the net zeta potential of the particles prior to the exposure to the cells and $24 \mathrm{~h}$ after their exocytosis. Fig. 2 shows the experimental results.

In both cases, for 'inhibitors' and 'mutants', only minor variations are observed in the hydrodynamic diameter and zeta potential before and after the exocytosis. These qualitative results clearly indicate that most of the exocytosed particles retain their colloidal stability, independently from the peptide-coating chosen here.

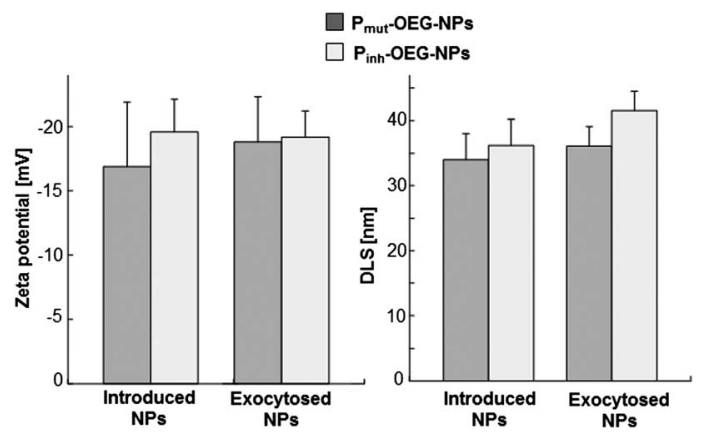

Fig. 2 Dynamic light scattering (DLS) and zeta potential measurements of peptide-coated nanoparticles ('inhibitors' and 'mutants') before the incubation with endothelial cells and after exocytosis. 


\section{Conclusions}

In conclusion, we monitored for the first time the endocytosis and exocytosis profile of two types of peptide-coated nanoparticles ('mutants' and 'inhibitors') of similar size and charge, which vary only in the peptide sequence. Although the two types of particles do not follow the same endocytosis pathways, they are taken up by the endothelial cells in greater numbers than just pegylated particles. They also appear to have a distinctively different exocytosis profile, suggesting that some of the 'mutant' particles are re-uptaken by the cells after $4 \mathrm{~h}$, while for a period of $6 \mathrm{~h}$ the 'inhibitor' particles are progressively exocytosed. DLS and zeta potential measurements indicate that both types of particles retain their colloidal stability after exocytosis.

\section{Experimental section}

Spherical gold NPs were prepared according to the well-established citrate reduction method, ${ }^{27}$ and stabilised with bis( $p$-sulfonatophenyl) phenyl phosphine dehydrate dipotassium salt (BSPP). Nanoparticles were then capped with monocarboxy (1-mercaptoundec-11-yl) hexaethylene glycol ligand, which chemisorbs directly onto the gold surface via the thiol group, and redispersed in $0.01 \mathrm{M}$ sodium borate buffer, $\mathrm{pH}$ 9. The peptides were coupled following a previously established protocol. ${ }^{28}$ Briefly, $\mathrm{P}_{\text {mut }}$ or $\mathrm{P}_{\mathrm{inh}}$ solutions $(10 \mu \mathrm{l}, 1 \mathrm{mg}$ $\mathrm{ml}^{-1}, \mathrm{MW}_{\mathrm{mut}}=922.1$, and $\mathrm{MW}_{\mathrm{inh}}=968.2 ;$ in $0.01 \mathrm{M}$ sodium borate buffer, $\mathrm{pH}$ 9) were added to OEG-NPs $(0.5 \mathrm{ml}, 1.5 \mathrm{nM}$; in $0.01 \mathrm{M}$ sodium borate buffer, $\mathrm{pH} 9$ ) and mixed. To this, aqueous solutions of coupling agents: EDC (1-(3-(dimethylamino)propyl)-3-ethyl-carbodiimidemethiodide, $5 \mu \mathrm{l}, 0.2 \mathrm{M}$ ) and sulfo-NHS ( $N$-hydroxysulfosuccinimide, $10 \mu \mathrm{l}, 0.2 \mathrm{M}$ ) were introduced. The reaction mixtures were stirred for $24 \mathrm{~h}$ at room temperature. Prior to incubation with cells, the functionalized particles were purified by triple centrifugation/decantation (16 $400 \mathrm{rpm}, 15 \mathrm{~min}$ ) and redispersed in M199 (20\% human serum) growth media.

Dynamic light scattering and the zeta potential of the functional particles before and after exocytosis were measured with a Zetasizer Nano ZS (Malvern Instruments Ltd). Disposable cuvettes (Malvern Instruments Ltd) were employed in dynamic light scattering (DLS) measurements, and disposable capillary cells in $\zeta$-potential measurements.

The total gold content in the cells and cell growth media was measured with ICP-AES. For the uptake studies, a confluent monolayer of HUVECs grown on a porcine gelatin $(0.2 \%$ in HBSS) pre-coated 12-well micro-plate was incubated with nanoparticles [(1.3 ml, $8 \mathrm{nM})$, in a 20\% human serum M199 growth medium)] for $4 \mathrm{~h}$ at $37^{\circ} \mathrm{C}$ in a humidified $5 \% \mathrm{CO}_{2}$ balanced air incubator. After treatment, cells were washed three times with $1 \times$ PBS and harvested with trypsin/EDTA solution ( $0.5 \mathrm{ml}$, Sigma-Aldrich). In the exocytosis studies, the cells, following $4 \mathrm{~h}$ incubation with nanoparticles, were washed three times with $1 \times$ PBS buffer, then returned to the incubator in $1 \mathrm{ml}$ of fresh growth media for an additional 2, 4 or $6 \mathrm{~h}$. The media were then collected, while the adherent cells were separately harvested with trypsin/EDTA.

The suspensions of the harvested cells were collected and digested by acid prior to ICP measurements. The number of gold atoms per nanoparticle was estimated from the average size of NPs taking into account the distances between atoms in the fcc crystal structure and the volume of a gold atom. At least three independent experiments were performed to estimate average numbers.

\section{Acknowledgements}

The authors would like to thank Dr Tilman Sanchez-Elsner for helpful discussions, the Biomedical Imaging Unit in Southampton General Hospital and the Nanobiotech facility, Italian Institute of Technology, Genoa for technical support. The financial support of the EPSRC, the Royal Society and the University of Southampton (USRG NanoScience) is gratefully acknowledged.

\section{References}

1 K. Saha, S. S. Agasti, C. Kim, X. Li and V. M. Rotello, Chem. Rev., 2012, 112, 2739-2779.

2 J. A. Barreto, W. O'Malley, M. Kubeil, B. Graham, H. Stephan and L. Spiccia, Adv. Mater., 2011, 23, H18-H40.

3 J. G. Huang, T. Leshuk and F. X. Gu, Nano Today, 2011, 6, 478-492.

4 S. J. Soenen, P. Rivera-Gil, J. Montenegro, W. J. Parak, S. C. De Smedt and K. Braeckmans, Nano Today, 2011, 6, 446-465.

5 F. M. Kievit and M. Zhang, Adv. Mater., 2011, 23, H217-H247.

6 E. C. Dreaden, A. M. Alkilany, X. Huang, C. J. Murphy and M. A. El-Sayed, Chem. Soc. Rev., 2012, 41, 2740-2779.

7 F. Zhao, Y. Zhao, Y. Liu, X. Chang, C. Chen and Y. Zhao, Small, 2011, 7, 1322-1337.

8 C. D. Walkey, J. B. Olsen, H. Guo, A. Emili and W. C. W. Chan, J. Am. Chem. Soc., 2012, 134, 2139-2147.

9 L. Xu., H. Kuang, C. Xu, W. Ma, L. Wang and N. A. Kotov, J. Am. Chem. Soc., 2012, 134, 1699-1709.

10 A. Curcio, R. Marotta, A. Riedinger, D. Palumberi, A. Falqui and T. Pellegrino, Chem. Commun., 2012, 48, 2400-2402.

11 H. Yang, S. Fung and M. Liu, Angew. Chem., Int. Ed., 2011, 50, $9643-$ 9646.

12 Ž. Krpetić, P. Nativo, I. A. Prior and M. Brust, Small, 2011, 7, 19821986.

13 V. See, P. Free, Y. Cesbron, P. Nativo, U. Shaheen, D. J. Ringden, D. G. Spiller, D. G. Fernig, M. R. H. White, I. A. Prior, M. Brust, B. Lounis and R. Levy, ACS Nano, 2009, 3, 2461-2468.

14 C. M. Jewell, J. Jung, P. U. Atukorale, R. P. Carney, F. Stellacci and D. J. Irvine, Angew. Chem., Int. Ed., 2011, 50, 12312-12315.

15 Ž. Krpetić, S. Saleemi, I. A. Prior, V. Sée, R. Qureshi and M. Brust, ACS Nano, 2011, 5, 5195-5201.

16 P. Nativo, I. A. Prior and M. Brust, ACS Nano, 2008, 2, 1639-1644.

17 P. C. Patel, D. A. Giljohann, W. L. Daniel, D. Zheng, A. E. Prigodich and C. A. Mirkin, Bioconjugate Chem., 2010, 21, 2250-2256.

18 M. D. Massich, D. A. Giljohann, A. L. Schmucker, P. C. Patel and C. A. Mirkin, ACS Nano, 2010, 4, 5641-5646.

19 D. Bartczak, T. Sanchez-Elsner, F. Louafi, T. Millar and A. G. Kanaras, Small, 2011, 7, 388-394.

20 D. Bartczak, O. L. Muskens, S. Nitti, T. Sanchez-Elsner, T. M. Millar and A. G. Kanaras, Small, 2012, 8, 122-130.

21 B. D. Chithrani and W. C. W. Chan, Nano Lett., 2007, 7, 15421550.

22 B. D. Chithrani, A. A. Ghazani and W. C. W. Chan, Nano Lett., 2006, 6, 662-668.

23 R. R. Arvizo, O. R. Miranda, M. A. Thompson, C. M. Pabelick, R. Bhattacharya, J. D. Robertson, V. M. Rotello, Y. S. Prakash and P. Mukherjee, Nano Lett., 2010, 10, 2543-2548.

24 D. Bartczak, O. L. Muskens, T. Millar, T. Sanchez-Elsner and A. G. Kanaras, Nano Lett., 2011, 11, 1358-1363.

25 A. M. Alkilany and C. J. Murphy, J. Nanopart. Res., 2010, 12, $2313-$ 2333.

26 D. B. Chithrani, Mol. Membr. Biol., 2010, 27, 299-311.

27 J. Turkevich, P. C. Stevenson and J. Hillier, Discuss. Faraday Soc., 1951, 11, 55-75.

28 D. Bartczak and A. G. Kanaras, Langmuir, 2011, 27, 10119-10123. 